\title{
Fast Atom Bombardment-Induced Condensation of Glycerol with Ammonium Surfactants. I: Regioselectivity of the Adduct Formation
}

\author{
Albert A. Tuinman and Kelsey D. Cook \\ Department of Chemistry, University of Tennessee, Knuxville, Tenuessee, USA
}

\begin{abstract}
Fast atom bombardment promotes condensation between trimethyl tetradecyl ammonium cations and the glycerol matrix. Bond formation at both the head and tail of the surfactant is demonstrated by low energy collision-induced dissociation (CID) of deuterium-labeled precursors, with a preponderance of the reaction apparently occurring at the tail. Two distinct CID pathways are identified for each kind of adduct (head- and tail-attack). Evidence is presented for the detection of distonic radical cations of the surfactant, complexed (solvated) with glycerol. (I Am Soc Mass Spectrom 1992, 3, 318-325)
\end{abstract}

$I^{2}$ $\mathrm{n}$ the ten years since its introduction [1] fast atom bombardment combined with mass spectrometry (FAB/MS) has become the most widely used desorption ionization technique. It is a method of sentinel importance, having increased by an order of magnitude the practical mass range routinely accessible by mass spectrometrists. By providing both quasimolecular ions and interpretable fragmentation, the method often offers a balance of molecular weight and structural information. Perhaps the most striking examples come from its use in protein sequencing [2].

These important features of FAB derive in large measure from its use of a liquid matrix to dissipate primary particle energy. However, this key benefit is not realized without cost. The appearance of FAB spectra is remarkably dependent on the choice of solvent. In addition to affecting the uverall semsitivity to a given analyte, the matrix can introduce artifacts [3] that would severely complicate spectral interpretation for true unknowns. Best studied among these is probably the bombardment-induced reduction of various compounds, [4-14] which depends sensitively not onty on matrix composition but also on primary beam parameters (flux and energy).

More complex examples of artifacts arising from intrinsic and beam-induced matrix chemistry have also been noted. For example, Dass and Desiderio [15] have described the fragmentation of peptide/glycerol ion adducts that contribute to ion intensities at massto-charge ratios above that for the protonated peptide.

Address reprint requests to Albert A. Tuirman, Department of Chemistry, University of Tennessee, Knoxville, TN 37996-1600.
Pang et al. [16] attributed such adducts to FABinduced reactions between the amine nitrogens and FAB-induced glycerol fragments. Such fragments were also invoked by Caldwell and Gross [17] to account for formation of adducts of chlorinated substrates, whereas Sethi et al. [18] invoked beam-induced analyte radicals to account for observed adducts of halogenated nucleotides.

Keough [19] has observed formation of covalent adducts formed by condensation reactions (with hydrogen climination) between glycerol solvent and cetyl pyridinium surfactant cations. Tandem mass spectrometry (MS/MS) of various methyl substituted analogs indicated that reaction occurred at the paraposition of the aromatic "head" group (i.e,. $1 \rightarrow 2$ ), a reasonable conclusion in light of the relative reactivities of the head and n-alkyl "tail" portions of the molecule. In the course of studies of the related surfactant trimethyl tetradecyl ammonium bromide [20] we noted evidence fur analogous adducts even with these relatively simple, saturated surfactants. Because these studies have involved selectively deuterated materials, it has been possible to assess the site(s) of adduction for comparison with Keough's results. The study has proved unexpectedly complicated, with a surprising time dependence in the apparent sites of preferred adduction. From a detailed understanding of this chemistry it should be possible to derive a better appreciation of the caveats necessary in interpreting FAB spectra. Such understanding must stem first from knowledge of the site(s) of adduct formation. Extraction of this information from spectra of labeled materials, with confirmation by MS/MS, is 
the subject of this study. In a subsequent article we will address the separate issue of time dependence and its implications concerning the roles of surface activity and gas- or condensed-phase chemistry in affecting FAB sensitivities [21-25].

\section{Experimental}

The bromide salts of 1 and 4 (see structures in Results and Discussion) were obtained from Aldrich Chemical Co. (Milwaukee, WI) and used without further purification. The bromide salts of 3,5 , and 6 , synthesized [26] from the appropriate deuterated precursors, as described elsewhere [20], were kindly provided by Dr. L. J. Magid.

Mass spectra were obtained on a hybrid mass spectrometer of $\mathrm{BEqQ}$ geometry, the $\mathrm{ZAB}-\mathrm{EQ}$ from $\mathrm{VG}$ Analytical (Manchester, England). In all cases $3 \mu \mathrm{g} / \mathrm{mg}$ solutions of the analyte in glycerol were deposited as a thin film on a 3-mm diameter brass target and bombarded with $\mathrm{Xe}$ atoms generated in an lon Tech (Middlesex, UK) Saddle Field source operated at $8 \mathrm{kV}$ with an emission current of $0.6 \mathrm{~mA}$. Film thickness on the target was estimated as $0.1-0.15 \mathrm{~mm}$ by examination under a microscope. For this film thickness adduct peaks became readily detectable after $\sim 3$-min bombardment time. For thicker films of the same analyte concentration the onset of adduct detection is signifcantly delayed. All spectra presented here are time averaged over a $10-\mathrm{min}$ period commencing $3 \mathrm{~min}$ after activation of the FAB gun.

Low energy collision-induced dissociation (CID) studies were done in the Q-scan mode, i.e,. separation of the precursor ion with MS-I (BE) $(\mathrm{m} / \Delta \mathrm{m} \geq$ 1000), followed by deceleration, then collision with Ar at $15 \mathrm{eV}$ in the collision quad (q), and analysis of the collision products with MS-II (Q). The Ar pressure measured with an ionization gauge outside $q$ was $2 \times 10^{-6}$ torr, representing -0.4 mtorr in the 120 $\mathrm{mm}$ long collision quadrupole, and a precursor peak size reduction of about $50 \%$. CID data were collected on a VG-11-250J data system by using the multichannel acquisition mode, a computer simulation of true multichannel acquisition that integrates spectra over several scans (here typically 40 scans at $15 \mathrm{~s} /$ scan).

\section{Results and Discussion}

$F A B$ spectra of labeled surfactants. Initial experiments probed the cetyl pyridinium cation 1 to allow comparison with MS/MS experiments by Keough [19]. Availability of the $D_{5}$-labeled cation 3 provided an opportunity to confirm his adduct structure 2 . Figure $1 a$ and $b$ show the FAB spectra of 1 and 3, respectively. In Figure 1a prominent adduct peaks are seen at masses $\mathrm{M1}+30, \mathrm{M1}+60$, and $\mathrm{M1}+90 \mathbf{u}^{1}$. These can be

\footnotetext{
${ }^{1}$ The designation $\mathrm{MX}(X=1-16)$ will be used throughout to designate the mass of the surfactant cation of compound $\boldsymbol{X}$.
}
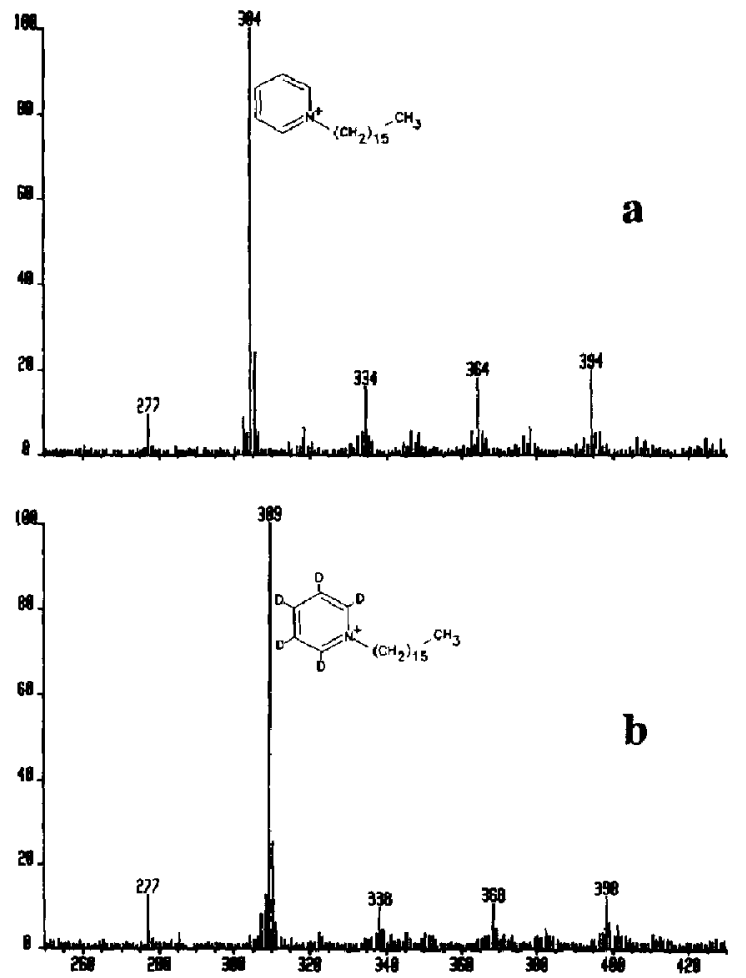

Figure 1. F^B spectra of (a) cetyl pyridinium cation (1) and (b) its $\mathrm{D}_{5}$ analog (3) in glycerol matrix.

explained [19] by reaction of radical products of glycerol beam damage (e.g., ${ }^{\cdot} \mathrm{CH}_{2} \mathrm{OH},{ }^{\circ} \mathrm{CH}(\mathrm{OH}) \mathrm{CH}_{2} \mathrm{OH}$, and $\left.\mathrm{C}(\mathrm{OH})\left(\mathrm{CH}_{2} \mathrm{OH}\right)_{2}\right)$ with radicals generated by abstraction of $\mathrm{H}^{\cdot}$ from 1 . For example, the ion at $\mathrm{M1}+90$ corresponds to $[1+\mathrm{G}-2 \mathrm{H}]$, where $\mathrm{G}$ denotes the solvent glycerol, i.e., G-2H accounts for the $90 \mathbf{u}$ addition. Attachment at the aromatic head group is demonstrated by the addition of only 29,59 , and 89 $\mathbf{u}$ in the analogous spectrum of 3 (Figure 1b), caused by the loss of $D \cdot$ from the aromatic ring (e.g., $[3+G$ $\mathrm{HD}]$ at $\mathrm{M3}+89$ ), rather than $\mathrm{H} \cdot$ from the alkyl chain.

Despite the absence of the reactive pyridyl group. the FAB spectrum of the trimethyl tetradecyl ammonium ion 4 (Figure 2) also shows evidence of glycerol adduct formation. In Figure 2 a adduct peaks are seen at masses M4 + 30, M4 + 60, and M4 + $90 \mathrm{u}$, as was the case for 1 [19]. Once again, predominant addition of only 29,59 , or $89 u$ for adducts of the corresponding D-labeled material 5 (Figure 3a) indicates that condensation occurs in the labeled part of the molecule, resulting, for example, in an adduct at M5 +89 for [5 + G-HD]. In this case, however, labeling is restricted to the hydrocarbon tail, which is therefore the principal site of attack. Structure 7 is a generic presentation of the $[\mathrm{M5}+\mathrm{G}-\mathrm{HD}]$ product of tail attack. We do not know the location(s) on the alkyl chain at which bond formation between the glycerol- 


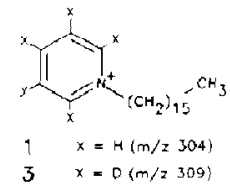

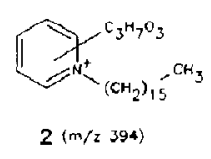<smiles>CN=CC[N+](C)(C)C</smiles>

$3 \quad x=P(m / 2309)$<smiles>CCN(C)C(C)(C)CC(=O)OC#N</smiles>

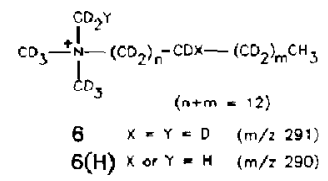

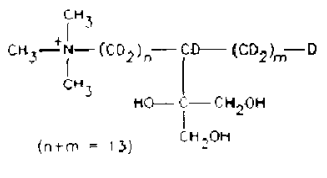

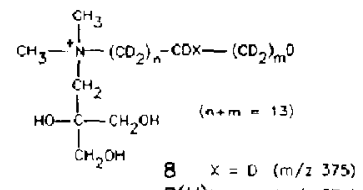

Plate I
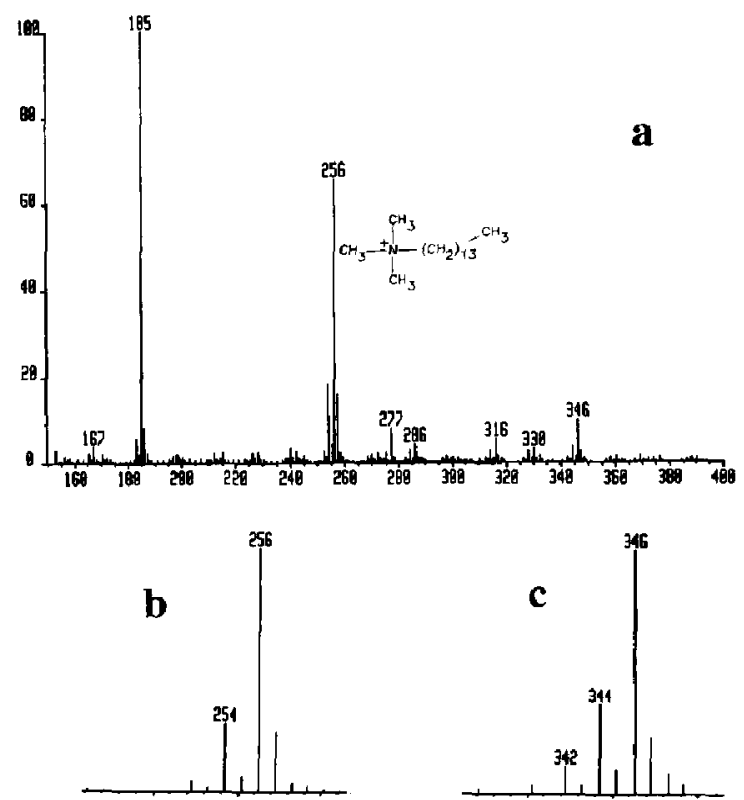

Figure 2. (a) FAB spectrum of trimethyl tetradecyl ammonium cation (4) in glycerol matrix, with the regions around (b) $\mathrm{m} / \mathrm{z}$ 256, and (c) $m / z 346$ expanded and normalized. Peaks at $m / z$ 185 and 277 are the proton bound glycerol dimer and trimer, respectively.
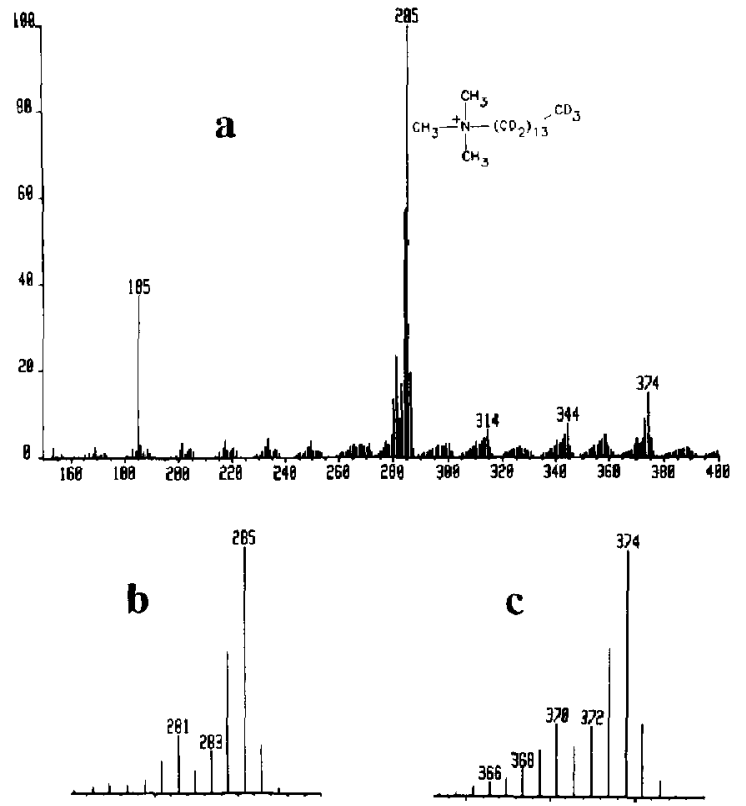

Figure 3. (a) FAB spectrum of $\mathrm{D}_{29}$-trimethyl tetradecyl ammonium cation (5) in glycerol matrix, with the regions around (b) $m / z 285$, and (c) $m / z 374$ expanded and normalized.

and surfactant-derived radicals occurs ${ }^{2}$. However, the reported propensity for beam damage condensations to occur at the center glycerol carbon $[28,29]$ prompts us to propose this site for bonding to the surfactant, as indicated in 7 .

It is important to note that the complex isotope clusters for the adducts of $\mathbf{5}$ are not consistent with the existence of a single adduct type. As reported in ref 20, ions within the cluster but at mass-to-charge ratio lower than $\mathrm{M5}+89$ can largely be explained by imperfect D-labeling of the surfactant (which gives rise to the precursor $5(\mathbf{H})$ at $\mathrm{m} / z 284$, containing one deuterium too few and one hydrogen too many), and by elimination of $D_{2}$. These cannot account for the unexpectedly high intensity at M5 $+90(\mathrm{~m} / \mathrm{z} 375)$, which is larger by about $35 \%$ than that expected if it were derived only from $7^{*}$, the natural ${ }^{13} \mathrm{C}$ isotope abundance of 7. A second contributor (besides $7^{*}$ ) to the $\mathrm{m} / z 375$ peak is therefore indicated. In view of the results with 1 and 3 , a likely candidate is adduct formation at the "head" of the surfactant, with ab straction of a hydrogen rather than a deuterium atom, and formation of the product ion 8 . This in turn suggests that there should be two isomers at $\mathrm{m} / \mathrm{z}$

\footnotetext{
${ }^{2}$ It is reasonable to expect that charge remote fragmentation (CRF) [27] might indicate site(s) of adduct formation, e.g., by the appearance of peaks $89 \mathrm{u}$ higher than those previously observed for the unadducted material [20]. I Infortunately, this was not the case. With the exception of additional peaks at P-104, P-92, and P-77, the CRF spectrum of M5 +89 (conditions as in ref 20 ) was essentially identical to that of M5.
} 
374: the tail-attached adduct 7 , and $8(\mathbf{H})$, the headattached adduct of the mislabeled $5(\mathbf{H})^{3}$.

In principle it would be possible to verify the hypothesis of reaction at both positions, and to quantify the ratio of those reactions, by acquiring a spectrum with sufficient resolution to separate the main constituents of the $\mathrm{M5}+90$ peak: the isobaric $\left(m / z\right.$ 375) species $7^{*}\left({ }^{13} \mathrm{CC}_{19} \mathrm{D}_{28} \mathrm{H}_{16} \mathrm{NO}_{3}\right)$ and 8 $\left(\mathrm{C}_{20} \mathrm{D}_{29} \mathrm{H}_{15} \mathrm{NO}_{3}\right)$. However, the resolution required for separation of those peaks $(\mathrm{m} / \Delta \mathrm{m}=128,000)$ makes this impractical. Instead, confirmation of adduct formation at both the head and tail of the surfactant was sought from MS/MS.

\footnotetext{
${ }^{3}$ As described previously [20], the extent of deuterium labeling at each site of 5 is high $(98.2 \%)$. However, the large number of supposedly deuterated sites in 5 (29) increases to roughly 1 in 3 the probability that one of these sites may be mislabeled, resulting in $-50 \%$ relative abundance at $m / z 284$.
}

Tandem mass spectrometry. MS/MS provides independent verification that both head and tail attack occur. Figure 4 presents the low energy CID spectra of four precursor ions, each of which is formed by FAB-induced condensation of glycerol with a surfactant. Three surfactants are represented that differ only in the extent and position of their deuterium labeling: the nondeuterated cation 4 (Figure $4 a$ ), the $D_{29}$ anolog 5 (which is deuterated only in the tail; Figure $4 \mathrm{~b}$ and c), and the $D_{35}$ analog 6 (which is deuterated in both head and tail; Figure 4d). Figure $4 b$ and $c$ differ in the choice of precursor ion; viz $\mathrm{P}=374$ and 375 , nominally represented by 7 and 8 , respectively. The vertical links in Figure 4 connect related CID fragments as follows. The persistent loss of $104 \mathrm{u}(\mathrm{P} \rightarrow \mathrm{P}-104)$ in each of the first three spectra (despite differences in tail labeling) indicates that the neutral fragment lost contains none of the hydrogens (deuteri-

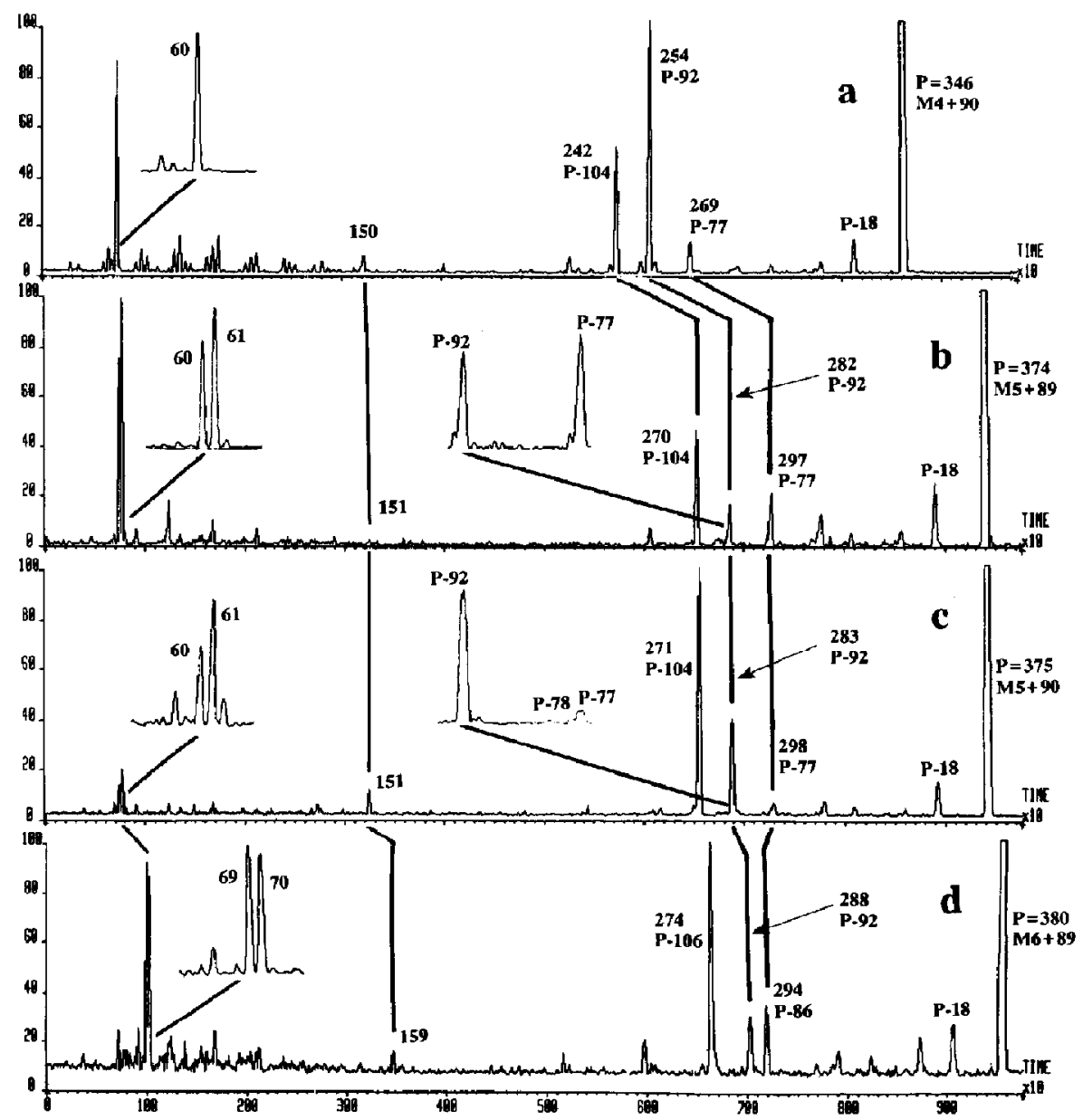

Figure 4. Low energy CID spectra of glycerol adducts of isotopically labeled surfactants: (a) precursor is the adduct at $m / z 346$ from trimethyl tetradecyl ammonium cation (4); (b) precursor is the adduct at $m / z 374$ from $D_{29}$-trimethyl tetradecyl ammonium cation (5); (c) precursor is the adduct at $m / z 375$ from $D_{29}$-trimethyl tetradecyl ammonium cation (5); and (d) precursor is the adduct at $m / z 380$ from $\mathrm{D}_{35}$-trimethyl tetradecyl ammonium cation (6). 


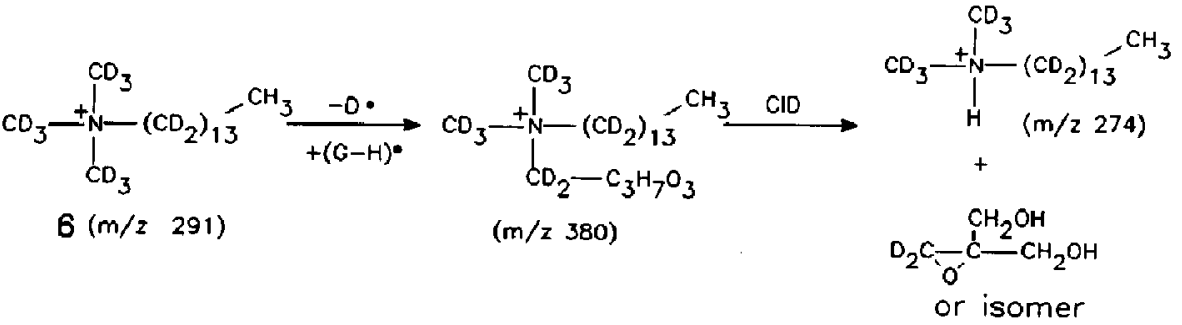

Scheme I

ums) originally located on the surfactant tail. The shift to P-106 in Figure 4d further indicates that the neutral fragment contains two deuteriums that were originally located on a head methyl group of 6 . Scheme I proposes reactions (adduct formation and CID fragmentation) that can reasonably account for these observations, using the $D_{35}$ surfactant cation (6) as the model. Based on Scheme I we conclude that the P-104 (P-106) fragments are characteristic of head attack.

By analogous reasoning the other CID fragment peaks highlighted in Figure 4 (except P-92, see below) can be assigned specifically to head- or tail-attack adduct precursors, as illustrated in Scheme II, using as an example the precursor peak at $\mathrm{m} / \mathrm{z} 374$ derived from analyte 5 (Figure $4 \mathrm{~b}$ ). Each of the four product ions (9-12) proposed in Scheme II derives from helerolytic cleavage of an $\mathrm{N}-\mathrm{C}$ bond, with retention of charge either on the nitrogen $(9,11$, and 12) or on the carbon (10).

The reaction $7 \rightarrow 9$ encompasses a hydrogen (from glycerol) or deuterium (from the hydrocarbon chain) shift to the charged entity, producing a doublet for 9 (cf Figure $4 \mathrm{~b}$, inset). The relative intensity at $m / z 60$ is higher than would be predicted based on purely statistical weighting of the 28 hydrocarbon $\mathrm{D}$ atoms versus just 7 glycerol hydrogens in 7 . However, it is known [30] that hydroxyl hydrogens remote from the charge site participate readily in such collisionally activated rearrangement/elimination reactions, and the observation of abundant $\mathrm{m} / \mathrm{z} 60$ does not necessarily imply glycerol attachment close to the charge site.

For ions with charge retention by $\mathrm{C}$ ( $\mathrm{P}-77$ and $\mathrm{P}-86)$, loss of the neutral trimethylamine is accompanied by loss of water. We propose that the fragmentation $7 \cdot 10$ proceeds by heterolytic cleavage of the $\mathrm{N}-\mathrm{C}$ bond to yield a carbocation that is capable of rapid charge migration and rearrangement via the intermediacy of protunated cyclopropanes [31, 32]. Once the charge reaches the carbon to which the glycerol remnant is attached, it is stabilized by dehydration, which takes place under the driving force of charge delocalization in the resulting allylic carbocation (Scheme III).

Observation of both types of CID fragments (151 and P-104 from head attack; 60, 61, and P-77 from tail

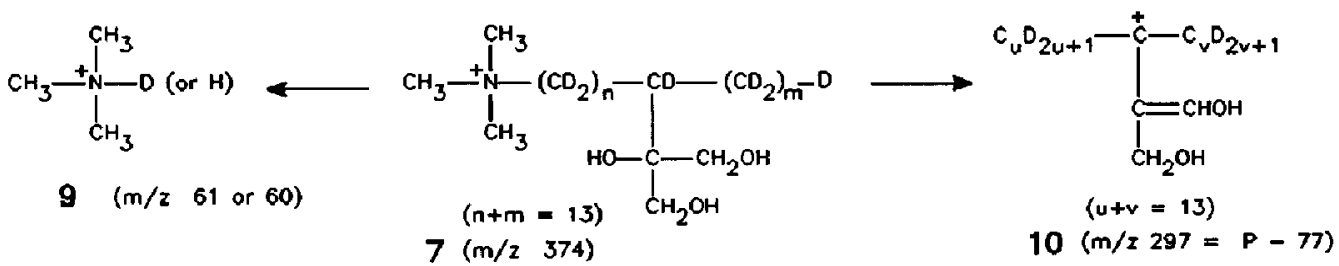<smiles>C[N+](C)(C)CCO[Pb]</smiles><smiles>C[N+](C)(CC(O)(CO)CO)[13C](=O)[O-]</smiles><smiles>[2H][N+](C)(C)CC(O)(CO)CO</smiles> 


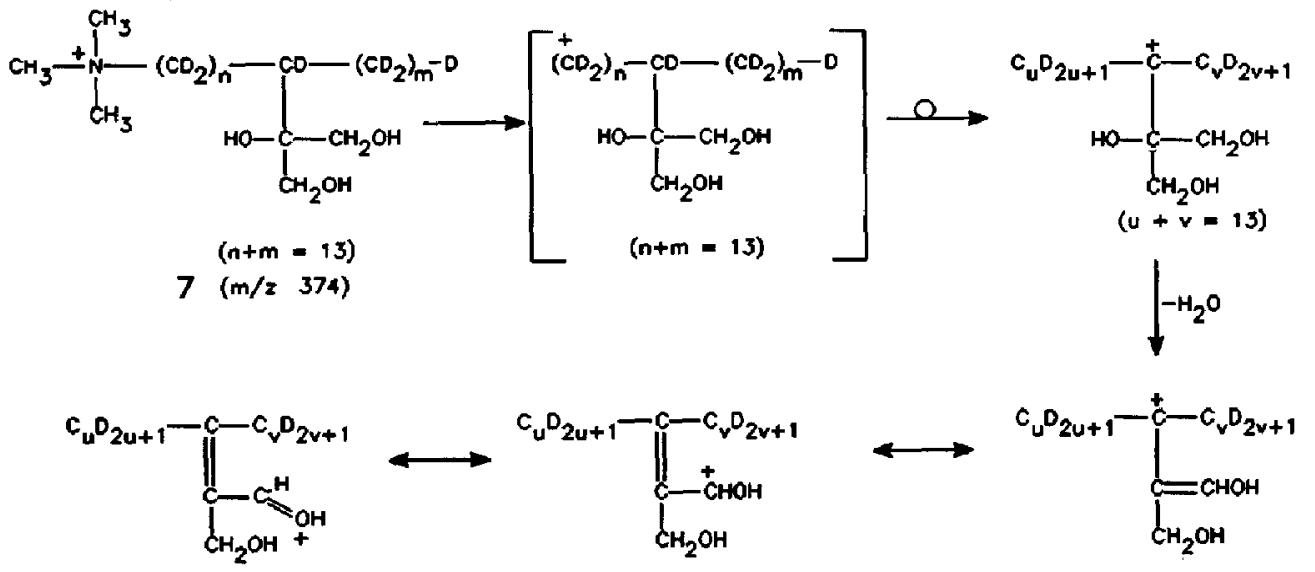

Scheme III

$10(\mathrm{~m} / z \quad 297=P-77)$

attack) in Figure $4 c$ confirms contributions at $P=375$ from both of the isobaric ions 8 and $7^{*}$, as proposed in the discussion of Figure $3 c$, above. Similarly, detection of both types of CID fragments in Figure $4 \mathrm{~b}$ confirms contributions to $P=374$ from the normal tail-attack adduct 7 , and from head attachment to the mislabeled material $\mathbf{5}(\mathbf{H})$, giving $\mathbf{8}(\mathbf{H})$. Note that fragments derived from tail-attached precursors are more intense in Figure $4 b$, while those associated with head attack are more intense in Figure $4 c$, reflecting the higher concentration of the "correctly" labeled material 5 compared with the "mislabeled" species $5(\mathbf{H})$ and $5^{*}$. The balance of head- and tail-attack fragments is more nearly equal in Figure $\mathbf{4 a}$ and $d$ because corresponding precursors are not isotopically differentiated in head and tail.

Possible rearrangement of distonic radical cations. The discussion thus far has tacitly assumed that the positions of hydrogen (or deuterium) abstraction from, and glycerol attachment to, the surfactant are identical. However, the possibility of tail $\leftrightarrow$ head radical transfer (e.g., as in Scheme IV) should not be ignored. Unfortunately, examination of the spectra can- not prove or disprove the reactions of Scheme IV unequivocally. For example, adducts derived through condensation of glycerol with 14 will be indistinguishable from products derived through "normal" head attack on $5(\mathbf{H})$, i.e., they are identical to $8(\mathbf{H})$. On the basis of available experimental evidence we can therefore not exclude $13 \rightarrow 14$ as a competitive step in a condensation reaction. However, only those intermediates that carry the radical site at positions 2 or 3 of the alkyl chain ( $n=1$ or 2 in Scheme IV) can produce the preferred [33] five- or six-membered cyclic transition states for $\mathbf{1 3} \rightarrow \mathbf{1 4}$. Even for these favorably configured radicals, energetic and statistical considerations argue against a significant contribution of reaction $13 \rightarrow$ 14. Primary carbon radicals (e.g., 14) are generally $2.5-3 \mathrm{kcal} / \mathrm{mol}$ less stable than similar secondary species (e.g., 13) $[34,35]$; the polarity of the ammonium cation will further elevate the relative energy of 14 [36b], making the rearrangement $13 \rightarrow 14$ significantly "uphill" in energy.

Of course, the same energetics inhibiting $13 \rightarrow 14$ should promote $15 \rightarrow 16$, except for the larger primary kinetic isotope effect, which should slow the transfer of a deuterium by a factor of roughly 2-8 [36a].<smiles>C[N+](C)(C)C(=O)OC(=O)OC(=O)OCc1ccccc1</smiles><smiles>CCOC(=O)COC(=O)[N+](C)(C)C</smiles>

$(n+m=13)$<smiles>C[N+](C)(C)C(=O)OC(=O)OC(=O)O</smiles>

15<smiles>C[N+](C)(C)CCCOC(=O)OCCCCO</smiles>

Scheme IV 
Glycerol radical attachment to 16 will generate adducts at $m / z$ 375, which should yield CID fragments at $m / z 61,62$, and P-78 instead of those expected at $m / z$ 60,61 , and P-77, as discussed above. However, the isobaric $(P=375)$ precursor $7^{*}$ also contributes to intensities at $m / z 61,62$, and P-78, by virtue of the (3 in 20) probability of the single ${ }^{13} \mathrm{C}$-atom residing in the head group methyls. Indeed, intensities at $m / z 61$ and 62 are higher (relative to 60 ) in Figure $4 \mathrm{c}$ than in $b$, as is the ratio of P-78 to P-77 (see insets in Figure $4 b$ and c). The much lower intensities of all fragments from tail-attack adducts in Figure $4 c$ (compared to b) precludes quantitative evaluation to ascertain the contribution (if any) of $[16+\mathrm{G} \cdot \mathrm{H}]$ to the precursor $\mathrm{P}=$ 375 . Therefore, a transition $15 \rightarrow 16$ may be indicated, but the experimental evidence is not conclusive.

Another potential complication deriving from analyte radical chemistry is the intermolecular hydrogen atom transfer from glycerol neutrals. For example, the reaction $13+\mathrm{C}_{3} \mathrm{H}_{8} \mathrm{O}_{3} \rightarrow 5(\mathrm{H})+\mathrm{C}_{3} \mathrm{H}_{7} \mathrm{O}_{3}$ should be energetically favored by $\sim 4-5 \mathrm{kcal} / \mathrm{mol}$ [37]. If this reaction were occurring, it would raise the concentration of $\mathbf{5}(\mathrm{H})$ and $\mathbf{6}(\mathrm{H})$ in the corresponding $F A B$ spectra. However, the field desorption spectra of these analytes display the same degree of mislabeling (within the experimental error) as do the $F A B$ spectra $(0.49$ for $5(\mathbf{H}) / 5$ and 0.38 for $6(\mathbf{H}) / 6$ in field desorption, compared with 0.48 and 0.38 , respectively, in FAB [20]). Thus, the intermolecular hydrogen transfer from matrix molecule to analyte radical appears to be insignificant. Why this reaction does not occur, despite its predicted exothermic character and the high concentration of the neutral reactant, is not clear.

Olefin/molecule and radical/molecule complexes. One final feature of Figure 4 worthy of note is the presence of P-92 in each of the CID spectra. Because of the invariance of the mass loss regardless of the isotope labeling of the analyte, we surmise loss of an intact glycerol molecule in each case, with the precursor being a complex of that glycerol and a derivative of the analyte. For the nondeuterated analyte 4 (Figure 4a), this derivative is most likely an olefin obtained through uxidative luss of $\mathbf{H}_{2}$ from the hydrocarbon chain [20] (i.e., $m / z \quad 346=\left[4-\mathrm{H}_{2} \cdot \mathrm{G}\right]$ ). By analogy, precursors losing $92 \mathrm{u}$ in Figure $4 \mathrm{~b}$ and $\mathrm{d}$ can be ascribed to $\left[5^{*}-D_{2} \cdot G\right]$ and $\left[6^{*}-D_{2} \cdot G\right]$ at 374 and 380 $\mathrm{u}$, respectively ( ${ }^{*}$ denoting ${ }^{13} \mathrm{C}$-containing ions, as above). The much smaller relative intensity of P-92 in Figure $4 b$ and $d$, compared to $a$, would then reflect the natural ${ }^{13} \mathrm{C}$ abundance of the complex.

The analogous candidate precursor ion at $m / z 375$ for luss of glycerol in Figure $4 \mathrm{c}$ would be [ $5^{*}-\mathrm{HID} \cdot \mathrm{G}$, requiring loss of $D^{\cdot}$ from $16^{*}$ to form an olefin $(\mathrm{m} / \mathrm{z}$ 283) capable of complexing with glycerol. This attribution is unsatisfactory because it contradicts the observed relative intensities: the intensity at P-92 in Figure $4 c$ is greater than that in $b$. The reverse should apply if $\left[5^{*}-\mathrm{HD} \cdot \mathrm{G}\right]$ and $[5-\mathrm{HD} \cdot \mathrm{G}]$ were the corre- sponding precursors because contributions from processes commencing with $5^{*}$ should be smaller than those commencing from 5 . We therefore tentatively ascribe a radical/molecule structure $[5-D \cdot G]$ to that isobaric precursor at $m / z \quad 375$ that loses an intact molecule of glycerol. This of course implies that glycerol loss for $\mathrm{P}=\mathbf{3 7 4}$ and 380 derives not only from the olefin/glycerol complexes described above, but also from the radical/glycerol complexes $[5(\mathbf{H})-\mathrm{D} \cdot \mathrm{G}]$ (for 374) and [6(H)-D - G] (for 380).

Considering the enforced distonic nature of the radical cation 13 , and the potentially large distance between radical and charge sites (up to 14 bonds), complex formation (solvation) may take place exclusively at the charge site (dipole complex) or exclusively at the radical site, or a mixture of both. The apparent lack of hydrogen/deuterium scrambling in the complex (as exemplified by the "clean" peak at P-92 of Figure $4 c^{4}$ ) may indicate the first possibility as the most likely. Work is continuing to verify the tentative assignment as a radical-cation/glycerol complex, and to establish its structure.

\section{Conclusions}

The FAB-induced condensation reaction of glycerol and the trimethyl tetradecyl ammonium ion is not regiospecific. Products result from abstraction of a hydrogen atom from either the long hydrocarbon chain or the head group methyls, with subsequent coupling of the resulting radical cation with a glycerol radical. If cross-sections and sensitivities are similar, relative intensities in Figure 3 suggest that the former (tail-attack) process dominates, perhaps reflecting the statistical weight of potential sites of attack (29 tail sites versus 9 head sites). This behavior is in stark contrast to the condensation of the cetyl pyridinium ion with glycerol, which appears to occur only on the head group. These different site specificities must stem from the greater reactivity of the aromatic head group of the pyridinium surfactant, which can donate a hydrogen radical to $\mathrm{FAB}$-generated glycerol radicals $[38,39]$. There is no conclusive evidence for intramolecular rearrangement of the radical cation intermediates (13 and 15) or of hydrogen transfer from neutral glycerol to thesc intermediates. One or both of the intermediate radicals is sufficiently stable to be observed as a complex with a neutral glycerol molecule in the low energy CID spcctrum. The sites of glycerol radical attachment (head or tail) can be differentiated in the low energy CID spectrum of the mixture, with two fragmentations specific to head, and two specific to tail attack. It has not been possible to locatize the site(s) of tail attack.

\footnotetext{
${ }^{4}$ The small peak at $P-93$ in Figure $4 b$ (inset) is attributable to the loss of ${ }^{13} \mathrm{C}$ containing glycerol from the precursor $\left[5-2 D \cdot G^{*}\right]$, which is isomeric to $\left[5^{*}-2 D \cdot G\right]$.
} 


\section{Acknowledgments}

This work was supported in part by a grant from the National Science Foundation ( \# CHE-88-22787). The UTK Chemistry Mass Spectrometry Center is funded by the Science Alliance, a State of Tennessee Center of Excellence. The NSF Chemical Instrumentation Program also contributed to the acquisition of the ZAB-EQ (grant \# CHE-86-09251).

\section{References}

1. Barber, M.; Bordoli, R. S.; Sedgwick, R. D.; Tyler, A. N. J. Chem. Soc., Chem. Commun. 1981, 325-327.

2. Biemann, K.; Martin, S. A. Mass Spectrom. Rev. 1987, 6, 1-75.

3. Detter, L. D.; Hand, O. W.; Cooks, R. G.; Walton, R. A. Mass Spectrom. Reo. 1988, 7, 465-502.

4. Santana-Marques, M. G. O.; Ferrer-Correia, A. J. V.; Gross, M. L. Arul. Chem. 1989, 61, 1442-1447.

5. Prókai, L.; Hsu, B-H; Farag, H.; Bodor, N. Anal. Chem. 1989, 61, 1723-1728.

6. Pelzer, G.; De Pauw, E.; Dung, D. V.; Marien, J. J. Phys. Chem. 1984, 88, 5065-5068.

7. Cerny, R. L,; Gross, M. L. Anal. Chemt. 1985, 52, 1160-1163.

8. Burinsky, D. J.; Dilliplane, R. L.; DiDonato, G. C.; Bush, K. L. Org. Mass Spectrom. 1988, 23, 231-235.

9. Gale, P. J.; Benz, B. L.; Chait, B.T.; Field, F. H.; Cotter, R. J. Anal. Chem. 1986, 58, 1070-1076.

10. Field. F. H. J. Phtys. Chen. 1982, 86, 5115-5123.

11. Ligon, W. V. Int. I. Mass Spectrom. Ion Phys. 1983, 52, 189-193.

12. Williams, D. H.; Findeis, A. F.; Naylor, S.: Gibson, B. W. J. Am. Chem. Soc. 1987, 109, 1980-1986.

13. Reynolds, J. D.; Cook, K. D. J. Amer. Soc. Mass Spectrom. 1990, 1, 149-157.

14. Nedermann, A.N. R.; Williams, D. H. Biolog. Mass Spectrom. 1991, 20, 289-291.

15. Dass, C.; Desiderio, D. M. Anal. Chem. 1988, 60, 2723-2729.

16. Pang, H.; Costello, C. E.; Biemann, K.; Presented at the 32nd Arnual Conference on Mass Spectrometry and Allied Topics; San Antonio, TX, 1984

17. Caldwell, K. A.; Gross, M. L.; Presented at the 39th Annual
Conference on Mass Spectrometry and Allied Topics; Nashville, TN, 1991.

18. Sethi, S. K.; Nelson, C. C.; McCloskey, J. A. Anal. Chem. 1984, 56, 1977-1979.

19. Keough, T. Int. J. Mass Spectrom. Ion Proc. 1988, 86, 155-168.

20. Tuinman, A. A.; Cook, K. D.; Magid, L. J. J. Am. Soc. Mass Spectrom. 1990, 1, 85-91.

21. Ligon, W. V.; Dorn, S. B. Int, I. Mass Spectrom. Ion Proc. 1981, 61, 3113-3122.

22. Lyon, P. A.; Hunt, S. Presented at the 36th Annual Conference on Mass Spectrometry and Allied Topics; San Francisco, CA, 1988.

23. Caldwell, K. A.; Gross, M. L. Anal. Chusn. 1989, 61, 496-499.

24. Allmaier, G. M. Rapid Commun. Mass Spectrom. 1988, 4, 74-76.

25. Todd, P. J. I. Amer. Soc. Mass Spectrom. 1991, 2, 33-44.

26. Scott, A. B.; Tartar, H. V. J. Amer. Chem. Soc. 1943, 65, 692-698.

27. Adams, J. Mass Spectrom. Rev. 1990, 9, 141-186.

28. Field, F. H. J. Phys. Chem. 1982, 86, 5115-5123.

29. Keough, T,; Ezra, F. S.; Russel, A. F.; Pryne, D. J. Org. Mass Spectrom. 1987, 22, 241-247.

30. Audier, H. E.; Milliet, A.; Perret, C.; Tahet, J. C.; Varenne, P. Nouveau J. Chim. 1977, 1, 269-270.

31. Tuinman, A. A.; Cook, K. D. Rapid Commun. Mass Spectrom. 1989, 3, 289-292.

32. Stahl, D.; Gäumann, T. Org. Mass Spectrom. 1977, 12, $761-765$.

33. Dóbé, S.; Bérces, T. In Chemical Kinetiks of Small Organic Kadicals: Vol. 1. Alfassi, Z. B., Ed.; CRC: Boca Raton, 1988; P 98.

34. Tsang, W. J. Am. Chem. Sac. 1985, 107, 2872-2880.

35. Castelhano, A. L.; Griller, D. J. Am. Chem. Soc. 1982, 104, $3655-3659$.

36. (a) Huang, R. L.; Goh, S. H., Ong, S. H. The Chemistry of Free Radicals; Edward Arnold: London, 1974; p 30. (b) Ibid, p. 108.

37. McMillen, D. F.; Golden, D. M. Ann. Rev. Phys. Chem. 1982, 33, 493-532.

38. Hvistendahl, G.; Undheim, K. Tetrahedron 1972, 28, 1737-1748.

39. Ellingsen, P.; Hvistendahl, G.; Undheim, K. Org. Mass Spectrom. 1978, 13, 455-458. 